\title{
Seleção massal e porcentagem de fibra em cultivar de algodoeiro colorido
}

\author{
Luiz Paulo de Carvalho( ${ }^{(1)}$, Paulo Augusto Vianna Barroso(1), José Aderaldo Trajano dos Santos ${ }^{(2)}$ \\ e Hamilton Santos Alves ${ }^{(2)}$
}

\begin{abstract}
(1)Embrapa Algodão, Caixa Postal 174, CEP 58107-720 Campina Grande, PB. E-mail: Ipaulo@cnpa.embrapa.br (2)Universidade Federal da Paraíba, Centro de Ciências Agrárias, Campus II, CEP 58397-000 Areia, PB. E-mail: hsantosalves@yahoo.com.br
\end{abstract}

\begin{abstract}
Resumo - Algodoeiros de fibras coloridas apresentam qualidade inferior em relação aos de fibra branca, além de menor potencial de rendimento, porque, comparados aos brancos, os coloridos foram pouco explorados em termos de melhoramento genético. Este trabalho teve como objetivo avaliar o efeito da seleção massal para porcentagem de fibra alta, média e baixa, dentro de uma população da cultivar BRS Verde, lançada em 2003. Quinhentas plantas da cultivar BRS Verde foram colhidas ao acaso e estratificadas em quatro classes quanto à porcentagem de fibra. As sementes de cada classe foram misturadas e participaram de um ensaio em blocos ao acaso com quatro tratamentos, mais a população original e quatro repetições. Ficou evidenciada a eficiência da seleção massal em alterar a média das populações selecionadas e o ganho de seleção foi de $11 \%$ quanto à porcentagem de fibra.
\end{abstract}

Termos para indexação: algodão, melhoramento, fibra verde, variabilidade genética.

\section{Mass selection for lint percentage in a colored cotton cultivar}

\begin{abstract}
The colored fiber cotton presents inferior quality in relation to the white one due to the fact that the colored was poorly studied as far as genetic breeding is concerned. The objective of this work was to verify the effect of mass selection for high, medium and low lint percentage in a population of the cotton cultivar BRS Verde. Five hundred plants were randomly harvested and after ginning, they were separated into four groups, based on lint percentage. Seeds within each class were mixed up to compose the treatments of a trial, ran as a complete randomized block design with four replicates. Treatments comprised four classes plus a sample of original population. Mass selection was efficient in changing the populations means and the overall genetic gain, concerning high lint percentage, was $11 \%$.
\end{abstract}

Index terms: cotton, breeding, green fiber, genetic variability.

\section{Introdução}

O linter e a fibra dos algodões tetraplóides ocorrem em cores que vão do branco a várias tonalidades de verde e marrom. Há relatos sobre os genes responsáveis por essas cores (Ware, 1932; Harland, 1935; Kohel, 1985).

O interesse pelo plantio de algodoeiros de fibra colorida vem aumentando na região Nordeste. Até 2004 foram lançadas duas cultivares que exibiam esse tipo de fibra, uma marrom claro e outra verde.

Os algodões coloridos apresentam, em média, rendimento $10 \%$ menor do que o branco e suas características de fibra são inferiores às dos brancos (Natural..., 1992). Verificou-se, além disso, que a seleção para maior intensidade da cor da fibra resulta em efeitos negativos nas características de fibra (Carvalho, 2003). Tais diferenças entre algodões brancos e coloridos são causadas, em grande parte, pelo fato de os algodoeiros coloridos não terem, ainda, sido submetidos a intensos trabalhos de melhoramento, como foram os de fibra branca (Carvalho, 2003).

A cultivar BRS Verde, lançada recentemente, possui baixa porcentagem de fibra, existindo, porém, variabilidade para essa característica (Carvalho, 2003). Entre as características buscadas no melhoramento do algodoeiro está a porcentagem de fibra, que é um dos componentes da produção de pluma. Além disso, os trabalhos de melhoramento buscam obter fibra com alto rendimento e de boa qualidade.

O objetivo deste trabalho foi avaliar o efeito da seleção massal para porcentagem de fibra alta, média e baixa, na cultivar de algodão BRS Verde. 


\section{Material e Métodos}

No ano de 2002, em um campo de 3 ha de multiplicação de sementes da cultivar BRS Verde, no Município de Barbalha, CE, foram marcadas 500 plantas ao acaso, antes do florescimento. Na colheita, essas plantas foram coletadas individualmente, e o algodão em caroço resultante foi enviado ao laboratório para determinação da porcentagem de fibra de cada planta. A partir desses dados, dividiu-se a população de plantas em quatro classes, de acordo com o porcentual de fibras (Tabela 1).

Considerando-se esses dados, compuseram-se quatro populações de plantas, misturando-se as sementes de plantas dentro de cada classe. Em 2003, as quatro populações participaram de um ensaio em blocos ao acaso, com quatro repetições, juntamente com a população original, representada por uma amostra de sementes do referido campo original, no Município de Missão Velha, CE. A parcela foi constituída de duas fileiras, no espaçamento de 1,0x0,20 m, com uma planta por cova após o desbaste. Na colheita foi retirada uma amostra padrão de 20 capulhos, em que foi determinada a porcentagem de fibra.

No cálculo das possíveis alterações da média populacional original com a seleção das diferentes classes, adotou-se o modelo:

$$
\begin{aligned}
& \overline{\mathrm{Y}}_{\mathrm{o}}=\mu_{\mathrm{o}}+\overline{\mathrm{e}} \\
& \overline{\mathrm{Y}}_{1}=\mu_{\mathrm{o}}-\mathrm{b}+\overline{\mathrm{e}}_{1} \\
& \overline{\mathrm{Y}}_{2}=\mu_{\mathrm{o}}+\mathrm{b}+\overline{\mathrm{e}}_{2} \\
& \overline{\mathrm{Y}}_{3}=\mu_{\mathrm{o}}+2 \mathrm{~b}+\overline{\mathrm{e}}_{3} \\
& \overline{\mathrm{Y}}_{4}=\mu_{\mathrm{o}}+3 \mathrm{~b}+\overline{\mathrm{e}}_{4}
\end{aligned}
$$

em que $\overline{\mathrm{Y}}_{0}$ é a média da população original; $\overline{\mathrm{Y}}_{1}$ é a média após seleção negativa, classe I; $\bar{Y}_{2}$ é a média após seleção positiva, classe II; $\bar{Y}_{3}$ é a média após seleção positiva, classe III; $\bar{Y}_{4}$ é a média após seleção positiva, classe IV.

O modelo proposto investiga se as alterações nas médias são lineares em relação às diversas direções da seleção. Cada classe, à exceção da primeira, aumenta um desvio padrão na média do caráter. A primeira diminui um desvio padrão.

Tabela 1. Divisão da população de algodoeiro cultivar BRS Verde, em classes, de acordo com a porcentagem de fibra.

\begin{tabular}{cccc}
\hline Classe & Número de plantas & Porcentagem de plantas & Porcentagem de fibra \\
\hline I & 49 & 9,8 & $\leq 25$ \\
II & 379 & 75,8 & 25,1 a 29,1 \\
III & 65 & 13,0 & 29,2 a 34,9 \\
IV & 7 & 1,4 & $\geq 35$ \\
\hline
\end{tabular}

Realizou-se uma análise de variância, em que foram calculados a herdabilidade do caráter, de acordo com a média dos tratamentos, e o coeficiente de variação genético. As médias foram comparadas pelo teste de Tukey a 5\% de probabilidade. Foi feita uma análise complementar para se avaliar o progresso devido à seleção, por meio do modelo linear $\mathrm{Y}=\mathrm{X} \beta+\xi$, em que ${ }_{n} \mathrm{Y}_{1}$ é um vetor de observações representado pela média dos tratamentos; ${ }_{n} \mathrm{X}_{\mathrm{p}}$ é uma matriz conhecida (matriz do delineamento), ${ }_{n} \xi_{1}$ é um vetor de variáveis aleatórias não observáveis tal que $\xi \sim \mathrm{N}\left(\varnothing ;\right.$ I $\sigma^{2}$ ); $\beta$ é o vetor de parâmetros a ser estimado.

Estabeleceu-se a matriz X como:

$X=\left[\begin{array}{rr}1 & 1 \\ 1 & -1 \\ 1 & 1 \\ 1 & 2 \\ 1 & 3\end{array}\right]$

Calculando-se o sistema de equações normais: $X^{\prime} X \hat{\beta}=X^{\prime} Y$, tem-se $\hat{\beta}=\left(X^{\prime} X\right)^{-1} X^{\prime} Y$.

Avaliou-se a adequação do modelo, calculando-se a soma de quadrados dos desvios do modelo $\mathrm{SQ}$ (desvios) da seguinte maneira: $S Q$ (desvios) $=\Sigma \overline{\mathrm{Y}}_{1}{ }^{2}-\mathrm{SQ}\left(\mu_{0}, \mathrm{~b}_{0}\right)$.

A soma dos quadrados que reflete o efeito da seleção SQ (b) foi calculada pela fórmula:

SQ (b) = SQ $\left(\mu_{0}\right.$, b) $-S Q\left(\mu_{0}{ }^{\prime}\right)$, em que $\mu_{0}{ }^{\prime}$ é a média em um modelo com apenas $\mu_{\mathrm{o}}$, comparado a um modelo com $\mu_{\mathrm{o}}$ e b. Utilizou-se como resíduo, nessa análise, o quadrado médio do resíduo da análise de variância em blocos ao acaso.

\section{Resultados e Discussão}

Os componentes da produção de pluma do algodoeiro são: o número de capulhos por planta, o tamanho de capulhos e a porcentagem de fibra (Poehlman, 1976). O tamanho do capulho é expresso pelo seu peso. A porcentagem de fibra refere-se ao peso de algodão em pluma, em relação ao peso de algodão em caroço. Portanto, o peso das sementes relaciona-se com a porcentagem de fibra. A porcentagem de fibra é fundamental para o produtor, porque é a parte da produção comercializada com maior valor econômico. Desse modo, são desejáveis cultivares com alta porcentagem de fibra, sem que se comprometa o tamanho da semente considerado ideal para uma boa germinação. 
Houve eficiência da seleção massal em alterar a média de cada população selecionada (Tabela 2). Quando foi realizada a seleção negativa para porcentagem de fibra, caso da classe I, verificou-se que a média dessa classe foi significativamente menor que a das classes III e IV, nas quais se realizou seleção positiva, para médias maiores.Quando foi realizada a seleção positiva, referente à classe II, a média dessa população foi significativamente menor que a seleção positiva da classe IV, na qual se selecionaram plantas com médias maiores.

A herdabilidade, tendo como unidade de seleção a média das progênies, foi elevada $(86,79)$, o que evidencia a existência de variabilidade genética entre as populações, bem como a relação entre os coeficientes da variação genética e ambiental $\left(\mathrm{CV}_{\mathrm{g}} / \mathrm{CV}_{\mathrm{e}}\right)$. A herdabilidade expressa a proporção da variância total que é atribuída ao efeito médio dos genes e tem um papel preditivo ao expressar a confiança do valor fenotípico como um guia para o valor genético (Falconer, 1987). Foi alta sua estimativa nessa população e verificou-se boa correspondência entre os valores fenotípicos dos indivíduos selecionados e seus valores genotípicos, o que propiciou os ganhos genéticos observados.

Turner Júnior (1953) verificou que os efeitos aditivos dos genes são mais importantes para explicar a variabilidade genética da produção de fibras. Do mesmo modo, Miller \& Marani (1963) e Lee et al. (1967) verificaram que a maior proporção da variabilidade genética dos três caracteres: porcentagem de fibra, peso de capulho e produção de fibras, era de natureza aditiva dos genes, o que demonstra possibilidades de ganhos genéticos com a seleção desses caracteres, como ficou evidenciado neste trabalho, quanto à porcentagem de fibra. $\mathrm{Na}$ análise da variância que testa o efeito da seleção para porcentagem de fibra, encontrou-se significância para progresso na seleção dessa característica e observou-se que não foram significativos os desvios em relação ao modelo admitido (Tabela 3). Houve progresso

Tabela 2. Comparação da porcentagem de fibra das populações de algodoeiro selecionadas com a população original da cultivar BRS Verde ${ }^{(1)}$.

\begin{tabular}{ccc}
\hline População & Porcentagem de fibra & População original (\%) \\
\hline I & $28,02 \mathrm{c}$ & 94,00 \\
II & $29,35 \mathrm{bc}$ & 97,67 \\
III & $31,75 \mathrm{ab}$ & 105,65 \\
IV & $32,70 \mathrm{a}$ & 108,81 \\
População original & $30,05 \mathrm{abc}$ & 100,00 \\
\hline (1)Médias seguidas da mesma letra não diferem entre si pelo teste de \\
Tukey a 5\% de probabilidade; média = 30,37\%; CV = 4,47\%; $\mathrm{CV}_{\mathrm{g}}=$ \\
5,73\%; $\mathrm{CV}_{\mathrm{g}} / \mathrm{CV}_{\mathrm{e}}=1,28 ; \mathrm{h}^{2}=86,79 \%$.
\end{tabular}

Tabela 3. Análise de variância para o modelo proposto para porcentagem de fibra em algodoeiro BRS Verde ${ }^{(1)}$.

\begin{tabular}{lcrc}
\hline Fator de variação & GL & QM & F \\
\hline Progresso na seleção (b) & 1 & 12,53 & $6,81^{* *}$ \\
Desvios do modelo & 1 & 4,73 & $2,57^{\text {ns }}$ \\
Erro & 12 & 1,84 & \\
\hline
\end{tabular}

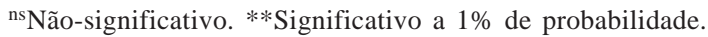

negativo (Tabela 2), quando se selecionaram os indivíduos da classe I, ou seja, com a porcentagem de fibra $<25 \%$. Nas demais classes houve ganho genético, à medida que se incrementou a seleção para valores mais altos da porcentagem de fibra (Tabela 2). Resolvendo-se o sistema matricial: $\mathrm{X}^{\prime} \mathrm{Xb}=\mathrm{X}^{\prime} \mathrm{Y}$, encontrou-se a estimativa de $b$, conforme a seguir:

$\hat{\beta}=\left(\begin{array}{l}\mu_{0} \\ b\end{array}\right)=\left(\begin{array}{c}29,27 \\ 1,106\end{array}\right)$

O ganho de seleção foi: $\hat{\mathrm{G}}_{\mathrm{s}}=\hat{\mathrm{b}}=1,106$ ou $\hat{\mathrm{G}}_{\mathrm{s}} \%=$ $(1,106 / 29.27)$ x $100=3,78 \%$, que reflete o progresso médio por classe de seleção. Considerando-se a população IV, em que se selecionaram os indivíduos com porcentual de fibra maior que $35 \%$, o $\mathrm{G}_{\mathrm{s}} \%$ foi de $11,34 \%$ para essa população, o que mostra eficiência de seleção massal em aumentar a média da população.

\section{Conclusões}

1. A cultivar BRS Verde apresenta variabilidade genética quanto à característica porcentagem de fibra.

2. A Seleção massal de plantas com maior porcentagem de fibras é eficiente no aumento da média dessa característica.

\section{Referências}

CARVALHO, L.P.; SANTOS, J.W. dos. Respostas correlacionadas do algodoeiro com a seleção para a coloração de fibras. Pesquisa Agropecuária Brasileira, v.38, p.79-83, 2003.

FALCONER, D.S. Introdução à genética quantitativa. Viçosa: UFV, 1987. 279p.

HARLAND, S.C. The genetics of cotton. XIV. The inheritance of brown lint in the New World cottons. Journal of Genetics, v.31, p.27-37, 1935.

KOHEL, R.J. Genetic analysis of fiber color variants in cotton. Crop Science, v.25, p.793-797, 1985. 
LEE, J.A.; MILLER, P.A.; RAWLINGS, J.O. Interaction of combining ability effects with environments in diallel crosses of upland cotton (Gossypium hirsutum L.) Crop Science, v.7, p.477-481, 1967.

MILLER, P.A.; MARANI, A. Heterosis and combining ability in diallel crosses of upland cotton, Gossypium hirsutum L. Crop Science, v.3, p.441-444, 1963.

NATURAL colors of cotton. Icac Recorder, v.10, p.3-5, 1992.
POEHLMAN, J.M. Mejoramiento genético del algodón. In: POEHLMAN, J.M. Mejoramiento genético de las cosechas. 5.ed. México: Limusa, 1976. p.329-352.

TURNER JUNIOR, J.H. A study of heterosis in upland cotton. II. Combining ability and inbreeding effects. Agronomy Journal, v.45, p.487-490, 1953.

WARE, J.V. Inheritance of lint colors in upland cotton. Journal of the American Society of Agronomy, v.24, p.550-562, 1932.

Recebido em 5 de agosto de 2004 e aprovado em 7 de março de 2005 